\title{
A Multicenter Randomized Clinical Trial of Primary Anastomosis or Hartmann's Procedure for Perforated Left Colonic Diverticulitis With Purulent or Fecal Peritonitis
}

\author{
Christian Eugen Oberkofler, MD, ${ }^{*}$ Andreas Rickenbacher, MD, ${ }^{*}$ Dimitri Aristotle Raptis, MD, MSc, ${ }^{*}$ \\ Kuno Lehmann, MD, ${ }^{*}$ Peter Villiger, MD, $\dagger$ Christian Buchli, MD, $\dagger$ Felix Grieder, MD, $\ddagger$ Hans Gelpke, MD, $\ddagger$ \\ Marco Decurtins, MD, $\ddagger$ Adrien A. Tempia-Caliera, MD, $\S$ Nicolas Demartines, MD, $\S$ Dieter Hahnloser, MD, $\S$ \\ Pierre-Alain Clavien, MD, PhD, ${ }^{*}$ and Stefan Breitenstein, MD*
}

\begin{abstract}
Objectives: To evaluate the outcome after Hartmann's procedure (HP) versus primary anastomosis (PA) with diverting ileostomy for perforated left-sided diverticulitis.

Background: The surgical management of left-sided colonic perforation with purulent or fecal peritonitis remains controversial. PA with ileostomy seems to be superior to HP; however, results in the literature are affected by a significant selection bias. No randomized clinical trial has yet compared the 2 procedures. Methods: Sixty-two patients with acute left-sided colonic perforation (Hinchey III and IV) from 4 centers were randomized to HP $(n=30)$ and to PA (with diverting ileostomy, $\mathrm{n}=32$ ), with a planned stoma reversal operation after 3 months in both groups. Data were analyzed on an intention-to-treat basis. The primary end point was the overall complication rate. The study was discontinued following an interim analysis that found significant differences of relevant secondary end points as well as a decreasing accrual rate (NCT01233713).
\end{abstract}

Results: Patient demographics were equally distributed in both groups (Hinchey III: $76 \%$ vs $75 \%$ and Hinchey IV: $24 \%$ vs $25 \%$, for HP vs PA, respectively). The overall complication rate for both resection and stoma reversal operations was comparable ( $80 \%$ vs $84 \%, P=0.813)$. Although the outcome after the initial colon resection did not show any significant differences (mortality $13 \%$ vs $9 \%$ and morbidity $67 \%$ vs $75 \%$ in HP vs PA), the stoma reversal rate after PA with diverting ileostomy was higher $(90 \%$ vs $57 \%, P=0.005$ ) and serious complications (Grades IIIb-IV: $0 \%$ vs $20 \%$, $P=0.046$ ), operating time (73 minutes vs 183 minutes, $P<0.001$ ), hospital stay ( 6 days vs 9 days, $P=0.016$ ), and lower in-hospital costs (US $\$ 16,717$ vs US $\$ 24,014$ ) were significantly reduced in the PA group.

Conclusions: This is the first randomized clinical trial favoring PA with diverting ileostomy over $\mathrm{HP}$ in patients with perforated diverticulitis.

Keywords: colonic perforation, diverticulitis, Hartmann's procedure, protective ileostomy, rectosigmoid resection

(Ann Surg 2012;256: 819-827)
W hile acute perforation of the left colon related to acute diverticulitis is common, a standardized therapeutic approach is still lacking. According to the current guidelines of the American Society of Colon and Rectal Surgeons, ${ }^{1}$ in the setting of purulent or fecal peritonitis (Hinchey III and IV), immediate resection of the diseased colonic segment with an end colostomy, that is, the Hartmann procedure (HP), is recommended, thus avoiding a primary anastomosis (PA). Indeed, currently HP still provides the treatment of choice in many surgical departments. ${ }^{2-4}$ In contrast, guidelines from the European Association for Endoscopic Surgery along with the results of several studies ${ }^{5-7}$ and 2 recent comprehensive literature reviews $s^{8,9}$ favor colonic resection with PA. In most of these trials, an additional diverting stoma was routinely performed; however, other reports have indicated favorable results even when a diverting stoma has been omitted, particularly in patients with purulent peritonitis. ${ }^{4,10}$

The putative advantage of HP is a shorter operating time with no risk of an anastomotic insufficiency. However, reversal of the colostomy might be a more extensive, time-consuming procedure with a significant risk for complications, when compared with the reversal of a simple diverting ileostomy. ${ }^{11,12}$ The rate of reversal after diverting ileostomy is reported to be much higher $(80 \%-90 \%)^{7,13}$ than closure of an end colostomy after HP (40\%-50\%). ${ }^{11,13}$ In a retrospective, case-matched control study published by our group in 2007, we found that PA with protective ileostomy was superior to HP, particularly with regard to a more frequent and safer stoma reversal. ${ }^{13}$

However, studies providing a high level of evidence on acute colonic perforation are yet lacking. Reported differences in mortality $(10 \%$ in PA and $40 \%$ in HP) as well as in morbidity ( $40 \%$ in PA and up to $70 \%$ in $\mathrm{HP})^{14}$ are based on potential high selection bias such as the tendency of sicker patients receiving an HP over a PA. ${ }^{15}$ Therefore, we initiated a multicenter randomized clinical trial to compare HP with PA with diverting ileostomy in patients presenting with perforated left colonic diverticulitis and purulent or fecal peritonitis (Hinchey III and IV).

\section{METHODS}

\section{Trial Design}

This multicenter randomized clinical trial was conducted in Switzerland; + + Department of Surgery, Cantonal Hospital, Chur, Switzerland; and $\ddagger$ Department of Surgery, Cantonal Hospital, Winterthur, Switzerland

$\mathrm{CEO}, \mathrm{AR}$, and DAR contributed equally as first authors.

Disclosure: The authors declare no conflicts of interest.

Supplemental digital content is available for this article. Direct URL citations appear in the printed text and are provided in the HTML and PDF versions of this article on the journal's Web site (www.annalsofsurgery.com).

Reprints: Stefan Breitenstein, MD, Department of Surgery, University Hospital Zurich, Raemistrasse 100, CH-8091, Zurich, Switzerland. E-mail: stefan. breitenstein@usz.ch.

Copyright (C) 2012 by Lippincott Williams \& Wilkins

ISSN: 0003-4932/12/25605-0819

DOI: $10.1097 /$ SLA.0b013e31827324ba
Switzerland to evaluate 2 surgical strategies (HP vs PA with diverting ileostomy) in patients presenting with perforated left-sided diverticulitis with purulent (Hinchey III) or fecal peritonitis (Hinchey IV), operated between 2006 and 2009. Both strategies were designed to include 2 consecutive operations: first, the rectosigmoid resection, and second, the stoma reversal. The unit of randomization was the patient at the time of the subsequent first operation (HP vs PA). The aim of the study was to confirm the hypothesis of superiority of PA with diverting ileostomy to HP. This randomized clinical trial was 
registered at clinicaltrial.gov (NCT01233713) and reported on the basis of the CONSORT statement. ${ }^{16}$

\section{Participants}

Eligible participants were German language-speaking adults (18 years of age or older) admitted for left-sided colonic perforation with purulent or fecal peritonitis (Hinchey III and IV) ${ }^{17}$ able to provide an informed consent. Patients without generalized peritonitis (Hinchey I and II) or with evidence of metastasis at presentation were not included. Participating centers of this study were the 2 university hospitals (Department of Surgery, University Hospital Zurich, Switzerland and Department of Visceral Surgery, University Hospital Lausanne, Lausanne, Switzerland) and 2 affiliated centers (Department of Surgery, Cantonal Hospital, Chur, Switzerland and Department of Surgery, Cantonal Hospital, Winterthur, Switzerland).

\section{Interventions}

HP refers to the surgical resection of the sigmoid colon with closure of the rectal stump and end colostomy, followed by a stoma reversal operation at a later stage. PA refers to the surgical resection of the sigmoid colon with PA and a diverting ileostomy, followed by a stoma reversal operation at a later stage. ${ }^{13}$ The stoma reversal for both procedures was set to take place up to 3 months after the first operation (HP or PA). Colonic anastomoses were performed by transanal circular stapling. Decisions to take down the splenic flexure or to clean the colon intraoperatively were made individually by the surgeons.

\section{Outcomes}

\section{Primary Outcome}

The overall postoperative complication rate (percent yes/no) including the first (colon resection), and the second operation (stoma reversal), assessed according to the therapy-oriented complication score, ${ }^{18}$ was defined as the primary end point of the study. The complication with the highest severity of individual patients was considered for the analysis.

\section{Secondary Outcomes}

Secondary end points were rates of serious postoperative complications (Clavien-Dindo ${ }^{18}$ grade $\geq$ IIIb overall, after the first and second operations), number of complications, stoma reversal rate, operating time, length of intensive care unit (ICU) stay, length of hospital stay in days, and in-hospital costs. The only outcome measure that was added after the trial had initiated was the long-term survival rate including a minimum of 2 years of follow-up.

\section{Cost Analysis}

The financial department of the hospitals provided the cost data by integrating complete in-hospital expenses including variable and fixed costs. The cost splitting started with the allocation of costs to the receiving cost units. Costs were directly attributed to each case, according to the services offered on the diagnostics, treatments, and bed-accompanying areas, as previously reported. ${ }^{19}$

\section{Sample Size}

The sample size calculation was based on pooled data derived from 15 published studies. , $7,10,20-26$ Of note, there were no randomized clinical trials, and the majority of them were retrospective. The estimated overall complication rate for HP was $80 \%$, whereas that for PA was $40 \%$ (ie, odds ratio, 6). Given the potential selection bias of these studies, we further hypothesized that a clinically relevant difference in the overall complication rate between HP and PA would be $50 \%$ (ie, odds ratio, 3 ). Thus, for the sample size calculation, we considered an overall complication rate of $72 \%$ for the HP and $47 \%$ for the PA (odds ratio, 3). With a 2-sided test (Fischer exact test), an allocation ratio of $1: 1$, an $\alpha$ error of 0.05 , and a power of $0.80,68$ patients had to be randomized in each group. Because the recruitment process in these emergency settings of acute illness was expected to be challenging, an interim analysis was scheduled after the inclusion of approximately $50 \%$ of the patients to assess the accrual rates and safety issues related to the study.

\section{Randomization}

A Web-based patient randomization service for multicenter clinical trials was used for the allocation of the participants (www. randomizer.at). ${ }^{27}$ The allocation ratio was $1: 1$ for both groups. The patients were enrolled to the study by the responsible surgeon at the time of admission to the emergency department, and the randomization took place during the induction of anesthesia by the responsible surgeon.

\section{Statistical Methods}

Continuous variables were compared with the Student $t$ test, the Mann-Whitney $U$ test, and the Kruskal-Wallis H test, where appropriate. Differences among proportions derived from categorical data were compared using the Fisher exact test and the Pearson $\chi^{2}$ test, where appropriate. Patient survival was assessed by the KaplanMaier function, the log-rank test was used for comparison purposes, and patients who died from carcinomatosis were censored. All $P$ values were 2-sided and considered statistically significant if $P<0.05$. The statistical analysis was performed on SPSS 18 for Mac.

\section{RESULTS}

\section{Patient Flow}

Figure 1 illustrates in detail the patient flow from the screening of potential participants to the final assessment. Fifty-two patients were not assessed for eligibility because of the surgeons' disagreement to enroll patient (40\% HP, 30\% PA with diverting ileostomy, $22 \%$ PA without diverting ileostomy, and $8 \%$ others). Of 83 eligible patients, 62 consecutive patients were definitively included in the study. Fifty percent of the patients were operated at the Department of Surgery, University Hospital Zurich, Switzerland whereas the others were treated in one of the other participating centers (25\% Department of Surgery, Cantonal Hospital Chur, Switzerland, 12.5\% Department of Surgery, Cantonal Hospital Winterthur, Switzerland and $12.5 \%$ Department of Visceral Surgery, University Hospital Lausanne, Lausanne, Switzerland). Thirty patients were randomized to HP and 32 to PA. One patient from the HP group received a PA, whereas 3 patients randomized for a PA received an HP. In all 4 cases, the decision to change the randomly allocated procedure was based on the surgeon's choice for the "apparent" benefit of the patients. Patient data were analyzed in the groups to which they had originally randomly assigned (intention-to-treat analysis). After the first operation, 7 patients died during the postoperative period and hence were not included in the denominator of the stoma reversal analysis.

\section{Outcome of the Interim Analysis}

In accordance with the study protocol, following enrollment of the 62 patients, an interim analysis was performed to assess the accrual rates and safety of the patients in this trial. The study was discontinued after consultation with the data-monitoring committee because significant differences were discovered in adequately powered relevant secondary outcomes (see later) and the low accrual rate, which particularly decreased over time from 25 patients in 2006 to 6 patients in 2009 . 


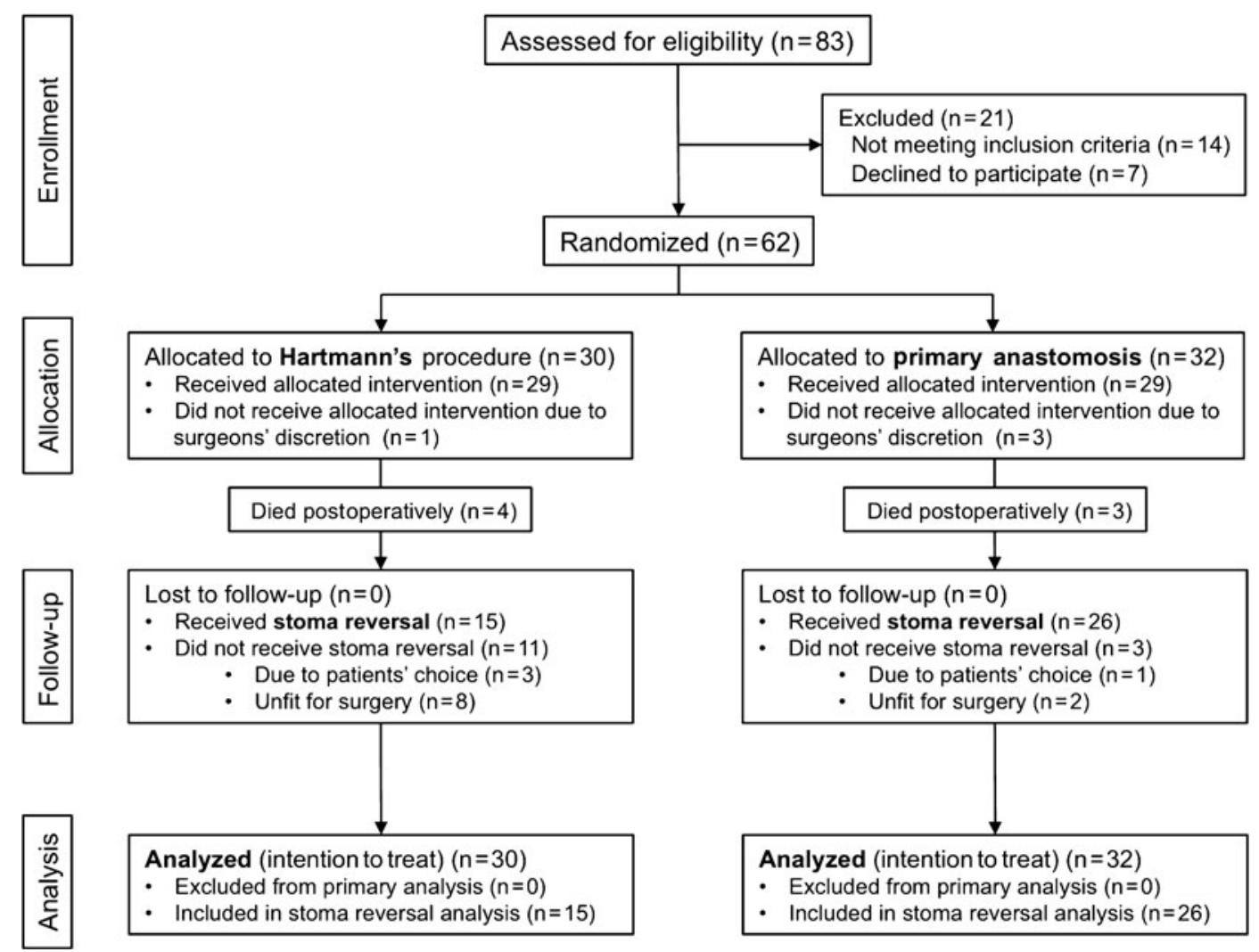

FIGURE 1. Patient flow chart. Adopted from Schulz et $\mathrm{al}^{16}$ (CONSORT group).

\section{Baseline Patient Characteristics}

Thirty patients were randomly allocated to HP, and 32 to PA with diverting ileostomy. Table 1 shows the patients' characteristics. The median age was 74 years in the HP group and 72 years in the PA group. Fewer male than female patients were included in the study, 9 $(30 \%)$ in HP and $12(34 \%)$ in PA. The American Society of Anesthesiologists, Charlson Index, ${ }^{28}$ and the inflammatory parameters were comparable. Similarly, the severity of peritonitis was equally distributed: purulent peritonitis (Hinchey 3 ) occurred in three quarters of the patients (77\% in HP and $75 \%$ in PA), whereas one quarter had feculent peritonitis (Hinchey $4: 23 \%$ in HP and 25\% in PA). The Mannheim Peritonitis Index ${ }^{29}$ was 22 and 24, respectively. With the exception of 1 operation, a board-certified surgeon was involved in all of the colonic resection procedures. There were no statistically significant differences among the parameters.

\section{Overall Outcome of Both Strategies}

Combining the first (colonic resection) and the second operations (stoma reversal), the overall complication rates (Clavien-Dindo grades I-V) were similar: $80 \%$ in the HP group and $84 \%$ in the PA group (Table 2). Figure S1, Supplemental Digital Content, available at: http://links.lww.com/SLA/A321, illustrates the distribution of complications according to their severity. Four patients died in the HP group (13\%), and 3 in the PA group (9\%). Severe complications such as reoperations and organ failure (grades IIIb-V) were also comparable (50\% in HP group and $44 \%$ in PA group). However, the total number of complications was significantly higher in the HP group (median 3 vs 1 , respectively, $P=0.004$ ). Other outcome parameters related to complications such as operating time, blood loss, hospital stay, and costs were similar in both groups.
Results of the first operation alone (resection alone for HP or PA) are summarized in Table 3. Although the operating time was slightly longer in the PA group (168 vs 208 minutes, $P=0.173$ ), all of the outcome parameters, including complications, were comparable in both groups. Figure 3 shows the distribution of the different types of complications.

\section{Rate and Safety of the Reversal Operation}

Only 15 of $26(58 \%)$ end colostomies (after HP) were eventually reversed, whereas the stoma reversal rate after ileostomy was significantly higher at $90 \%(26 / 29, P<0.012)$. The reason for not having the stoma reversed was the operative risk, as assessed by the surgeon, or the patient's choice (Table 4). Two of 3 patients without stoma reversal in the PA group were deviated to HP during the first operation and were felt to be unfit for a laparotomy. Diverting ileostomies were reversed much earlier than the end colostomies after HP (median 3 months vs 6 months, respectively).

Although the difference of postoperative complications ( $40 \%$ in $\mathrm{HP}$ vs $23 \%$ in PA) was not statistically significant, the rate of severe complications (grades IIIb-IV) $(20 \%$ vs $0 \%, P=0.046)$, as well as the total number of complications per patient (median 1 vs median $0, P<0.001$ ), was significantly higher in the HP group (Fig. 2). Regarding specific types of complications, anastomotic dehiscence, sepsis, and bleeding occurred only after reversal of the end colostomy (Fig. 3). Furthermore, the duration of the operation (183 minutes vs 73 minutes, $P<0.001$ ) as well as the hospital stay (9 days vs 6 days, $P=0.016$ ) was significantly longer in the HP group (Table 4). 
TABLE 1. Baseline Demographic, Clinical, and Perioperative Characteristics for Each Group

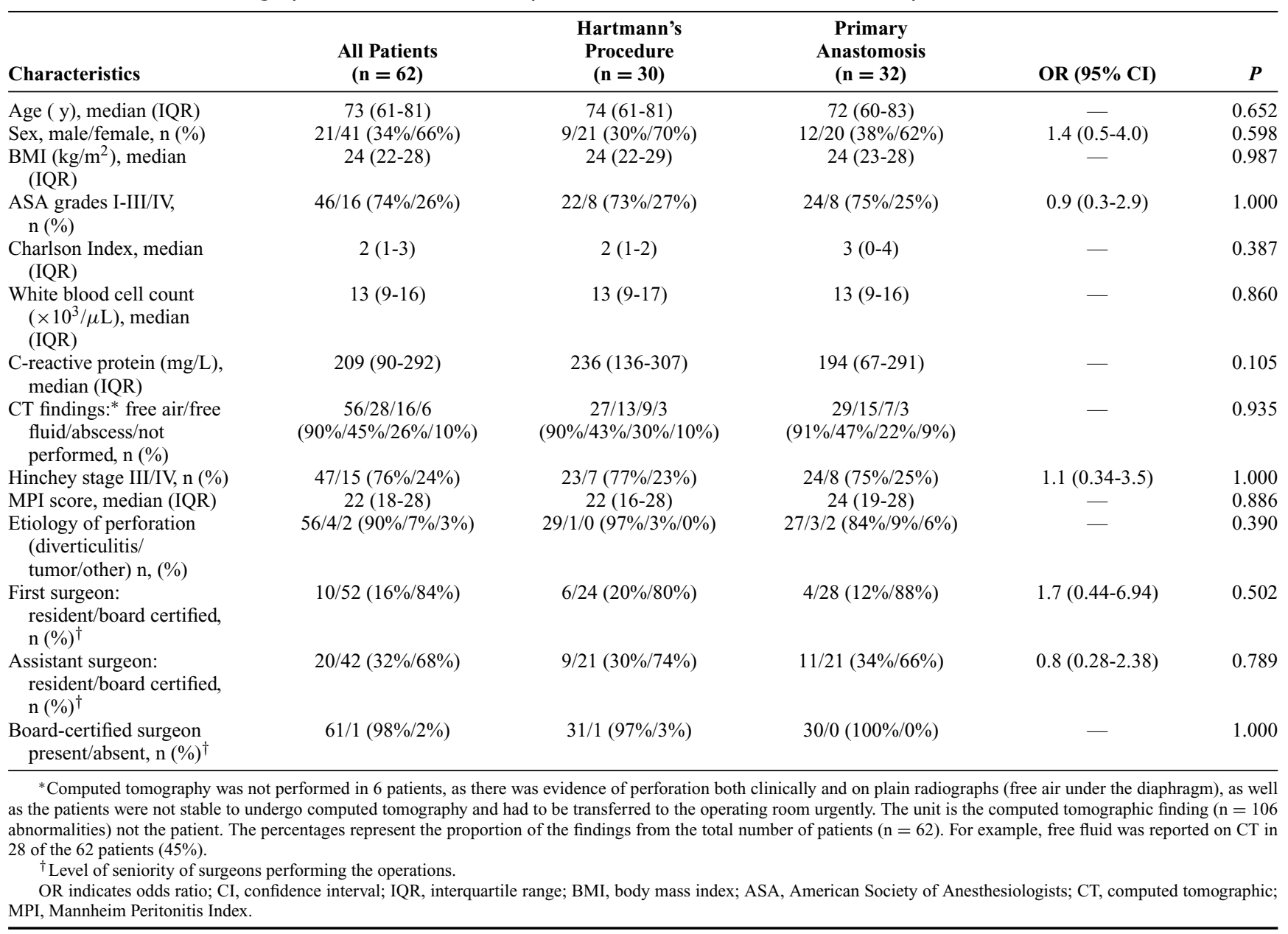

\section{Long-Term Survival}

There was no significant difference in the survival rates between HP and PA (Fig. S2, Supplemental Digital Content, available at: http://links.lww.com/SLA/A321). The median follow-up time was 47 months (95\% confidence interval, 38-55). The overall 1-, 3-, and 5 -year patient survival from randomization to death was $92 \%, 81 \%$, and $64 \%$, respectively. Patients who died from carcinomatosis were censored.

\section{DISCUSSION}

This is the first randomized clinical trial to compare the 2 most common 2-staged procedures in acute left-sided colonic perforation with purulent or fecal peritonitis. The study demonstrates a superiority of PA with diverting ileostomy to HP. The advantages mainly relate to the ileostomy reversal, which was more likely to occur and associated with less severe complications than the colostomy reversal after HP.

Several distinct surgical procedures have been used and studied in the management of perforated left-sided colonic perforation. Although the advantages of an approach with primary resection over secondary resection (first stage: perforation sutured and colostomy; second stage: sigmoid resection with or without reversal of colostomy) were established in a multicenter randomized study, ${ }^{30}$ there is an ongo- ing debate whether to perform a PA, with or without diverting stoma, or an end colostomy (HP). The selection bias of available retrospective studies is thought to be the most likely reason why results after HP are inferior to those after PA. It was repeatedly mentioned that low-risk patients tend to be treated with PA, whereas high-risk patients (aged, with comorbidities, and more severe peritonitis) receive an $\mathrm{HP}^{30-32}$ Such bias was also well documented in a systematic review by Salem and Flum. ${ }^{7}$ Recently, we attempted to address this selection bias by performing a retrospective case-matched controlled study. This study similarly showed the superiority of PA with diverting ileostomy to HP. ${ }^{13}$ However, only randomized clinical trials can provide high level of evidence to answer convincingly the clinically relevant question on how to manage acute left-sided colonic perforations.

This study was designed as a so-called "pragmatic trial" 33 for the treatment of acute colonic perforation. Several challenges related to the study design had to be addressed. Four centers participated in this study to compare 2 substantially different surgical procedures, providing a balanced surgical expertise (Table 1). Because of the emergency settings of this disease, the allocation process was somewhat problematic. Although several patients could have been assessed for eligibility, some surgeons declined trial participation, making the recruitment process difficult. This reluctance of surgeons markedly increased toward the end of the study period. It is known that surgeons may be less tolerant of uncertainty about the effectiveness of 
TABLE 2. Outcomes Related to the Combined First (Resection) and Second (Stoma Reversal) Procedures (HP vs PA)

\begin{tabular}{|c|c|c|c|c|c|}
\hline $\begin{array}{l}\text { Outcomes (Combined } \\
\text { First } \pm \text { Second Operation) }\end{array}$ & All Patients $(n=62)$ & $\begin{array}{c}\text { Hartmann's } \\
\text { Procedure } \pm \\
\text { Reversal }(n=30)\end{array}$ & $\begin{array}{c}\text { Primary } \\
\text { Anastomosis } \pm \\
\text { Reversal }(n=32)\end{array}$ & OR $(95 \% \mathrm{CI})$ & $\boldsymbol{P}$ \\
\hline $\begin{array}{l}\text { Operation time }(\mathrm{min}), \\
\text { median }(\mathrm{IQR})\end{array}$ & $300(217-363)$ & $383(280-460)$ & $240(205-330)$ & - & 0.002 \\
\hline $\begin{array}{l}\text { Blood loss (mL) } \\
\text { median (IQR) }\end{array}$ & $300(143-600)$ & $300(200-600)$ & $220(120-500)$ & - & 0.296 \\
\hline $\begin{array}{l}\text { Blood transfusions (units), } \\
\text { mean (SD) }\end{array}$ & $0.5 \pm 1.5$ & $0.2 \pm 0.6$ & $0.7 \pm 1.9$ & - & 0.454 \\
\hline $\begin{array}{l}\text { Intensive care unit stay (d), } \\
\text { median (IQR) }\end{array}$ & $1(1-3)$ & $2(1-3)$ & $1(1-4)$ & - & 0.620 \\
\hline $\begin{array}{l}\text { Hospital stay (d) } \\
\text { median (IQR) }\end{array}$ & $23(16-36)$ & $24(16-40)$ & $22(15-32)$ & - & 0.521 \\
\hline $\begin{array}{l}\text { Complications (grades I-V) } \\
\text { yes/no, n (\%) }\end{array}$ & $51 / 11(82 \% / 18 \%)$ & $24 / 6(80 \% / 20 \%)$ & $27 / 5(84 \% / 16 \%)$ & $0.74(0.20-2.74)$ & 0.764 \\
\hline $\begin{array}{l}\text { Total number of } \\
\text { complications, } \\
\text { median (IQR) }\end{array}$ & $2(1-3)$ & $3(2-4)$ & $1(1-3)$ & - & 0.004 \\
\hline $\begin{array}{l}\text { Serious complications, } \\
\text { (grades IIIb-V), n (\%) }\end{array}$ & $29(47 \%)$ & $15(50 \%)$ & $14(44 \%)$ & $1.29(0.47-3.50)$ & 0.799 \\
\hline Hospital mortality, n (\%) & $7(11 \%)$ & $4(13 \%)$ & $3(9 \%)$ & $0.67(0.14-3.29)$ & 0.703 \\
\hline $\begin{array}{l}\text { In-hospital cost (USD), } \\
\text { mean (SD) }\end{array}$ & $76,464 \pm 53,892$ & $77,943 \pm 50,352$ & $75,208 \pm 58,002$ & - & 0.880 \\
\hline $\begin{array}{l}\text { In-hospital cost (USD), } \\
\text { median (IQR) }\end{array}$ & $\begin{array}{c}65,544 \\
(42,256-92,785)\end{array}$ & $\begin{array}{c}76,248 \\
(55,319-94,679)\end{array}$ & $\begin{array}{c}60,926 \\
(42,256-84,744)\end{array}$ & - & 0.557 \\
\hline
\end{tabular}

OR indicates odds ratio; CI, confidence interval; IQR, interquartile range; USD, US dollars.

TABLE 3. Outcomes Related to the First (HP vs PA) Procedure Only

\begin{tabular}{|c|c|c|c|c|c|}
\hline $\begin{array}{l}\text { Outcomes (First } \\
\text { Operation Only) }\end{array}$ & All Patients $(n=62)$ & $\begin{array}{c}\text { Hartmann's } \\
\text { Procedure }(n=30)\end{array}$ & $\begin{array}{c}\text { Primary } \\
\text { Anastomosis } \\
(n=32)\end{array}$ & OR $(95 \% \mathrm{CI})$ & $\boldsymbol{P}$ \\
\hline $\begin{array}{l}\text { Operation time }(\mathrm{min}) \\
\text { median }(\mathrm{IQR})\end{array}$ & $180(147-225)$ & $168(130-220)$ & $208(150-233)$ & - & 0.173 \\
\hline $\begin{array}{l}\text { Blood loss (mL) } \\
\text { median (IQR) }\end{array}$ & $100(200-575)$ & $300(100-600)$ & $200(100-500)$ & - & 0.542 \\
\hline $\begin{array}{l}\text { Intraoperative blood } \\
\text { transfusions (units) } \\
\text { mean (SD) }\end{array}$ & $0.3 \pm 0.8$ & $0.2 \pm 0.6$ & $0.4 \pm 1$ & - & 0.620 \\
\hline $\begin{array}{l}\text { Intensive care unit stay (days), } \\
\text { median (IQR) }\end{array}$ & $1(1-3)$ & $2(1-3)$ & $1(1-4)$ & - & 0.620 \\
\hline $\begin{array}{l}\text { Hospital stay (d) } \\
\text { median (IQR) }\end{array}$ & $17(13-27)$ & $18(14-27)$ & $16(13-25)$ & - & 0.622 \\
\hline $\begin{array}{l}\text { Complications } \\
\text { (Clavien-Dindo I-V) } \\
\text { yes/no, n (\%) }\end{array}$ & $51 / 11(82 \% / 18 \%)$ & $24 / 6(80 \% / 20 \%)$ & $27 / 5(84 \% / 16 \%)$ & $0.74(0.20-2.74)$ & 0.764 \\
\hline $\begin{array}{l}\text { Total number of } \\
\text { complications, } \\
\text { median (IQR) }\end{array}$ & $1(1-2)$ & $2(1-2)$ & $1(1-2)$ & - & 0.198 \\
\hline $\begin{array}{l}\text { Serious complications, } \\
\text { (Clavien-Dindo IIIb-V), } \\
\mathrm{n}(\%)\end{array}$ & $26(42 \%)$ & $12(40 \%)$ & $14(44 \%)$ & $0.86(0.31-2.36)$ & 0.802 \\
\hline Hospital mortality, n (\%) & $7(11 \%)$ & $4(13 \%)$ & $3(9 \%)$ & $0.67(0.14-3.29)$ & 0.703 \\
\hline $\begin{array}{l}\text { In-hospital cost (USD), } \\
\text { mean (SD) }\end{array}$ & $61,447 \pm 52,851$ & $60,992 \pm 47,834$ & $61,834 \pm 58,010$ & - & 0.962 \\
\hline $\begin{array}{l}\text { In-hospital cost (USD), } \\
\text { median (IQR) }\end{array}$ & $\begin{array}{c}46,546 \\
(33,492-76,415)\end{array}$ & $\begin{array}{c}47,527 \\
(37,037-78,655)\end{array}$ & $\begin{array}{c}45,059 \\
(33,492-66,232)\end{array}$ & - & 0.684 \\
\hline
\end{tabular}




\begin{tabular}{|c|c|c|c|c|c|}
\hline $\begin{array}{l}\text { Outcomes (Second } \\
\text { Operation Only--Stoma } \\
\text { Reversal) }\end{array}$ & All $(n=41)$ & $\begin{array}{l}\text { Hartmann's } \\
\text { Procedure } \\
(\mathrm{n}=15)\end{array}$ & $\begin{array}{c}\text { Primary } \\
\text { Anastomosis } \\
(\mathrm{n}=\mathbf{2 6})\end{array}$ & OR $(95 \%$ CI $)$ & $P$ \\
\hline $\begin{array}{l}\text { Operation duration (min), } \\
\text { median (IQR) }\end{array}$ & $110(66-158)$ & $183(150-255)$ & $73(60-90)$ & - & $<0.001$ \\
\hline $\begin{array}{l}\text { Blood loss (mL) } \\
\text { median (IQR) }\end{array}$ & $25(5-50)$ & $45(5-150)$ & $20(5-40)$ & - & 0.187 \\
\hline $\begin{array}{l}\text { Hospital stay (d) } \\
\text { median (IQR) }\end{array}$ & $8(5-11)$ & $9(6-17)$ & $6(4-10)$ & - & 0.016 \\
\hline $\begin{array}{l}\text { Complications } \\
\text { (Clavien-Dindo I-V) } \\
\text { yes/no, n (\%) }\end{array}$ & $12 / 29(30 \% / 70 \%)$ & $6 / 9(40 \% / 60 \%)$ & $6 / 20(23 \% / 76 \%)$ & $2.1(0.53-8.41)$ & 0.299 \\
\hline $\begin{array}{l}\text { Total number of } \\
\text { complications, } \\
\text { median (IQR) }\end{array}$ & $0(0-1)$ & $1(1-1)$ & $0(0-0)$ & - & $<0.001$ \\
\hline $\begin{array}{l}\text { Serious complications, } \\
\text { (Clavien-Dindo IIIb-V), } \\
\mathrm{n}(\%)\end{array}$ & $3(7 \%)$ & $3(20 \%)$ & $0(0 \%)$ & - & 0.046 \\
\hline $\begin{array}{l}\text { In-hospital cost (USD), } \\
\text { mean (SD) }\end{array}$ & $19,844 \pm 14,362$ & $24,014 \pm 15,472$ & $16,717 \pm 11,819$ & - & 0.168 \\
\hline $\begin{array}{l}\text { In-hospital cost (USD), } \\
\text { median (IQR) }\end{array}$ & $14,362(9,259-26,172)$ & $\begin{array}{c}19,758 \\
(11,777-33,428)\end{array}$ & $12,573(9087-20,887)$ & - & 0.178 \\
\hline Stoma reversed, $\mathrm{n}$ ( $\%$ of total) & $41(66 \%)$ & $15(57 \%)$ & $26(90 \%)$ & $0.16(0.05-0.59)$ & 0.005 \\
\hline
\end{tabular}

OR indicates odds ratio; CI, confidence interval; IQR, Interquartile range; USD, US dollars.

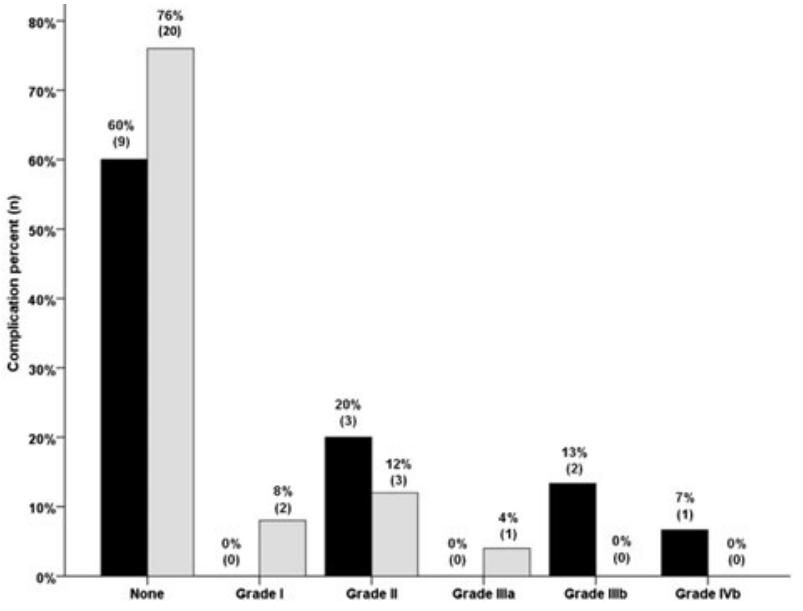

FIGURE 2. Second operation (stoma reversal) only complications for HP (black bars) versus PA (gray bars) defined according to the Clavien-Dindo classification. ${ }^{18}$

alternative treatments compared with physicians. ${ }^{33}$ Particularly in an emergency setting, typically facing the need of a rapid decision out of the regular schedule, some surgeons wish to make their own decision on the type of intervention. ${ }^{34}$ After the inclusion of 62 patients, the data-monitoring committee suggested to stop the trial, not only because of the lowered accrual rate but also for reasons of safety. This interim analysis revealed adequately powered significant differences in several relevant secondary end points in favor of PA with protective ileostomy.

Several prognostic factors influencing morbidity and mortality in acute left-sided colonic perforation, such as age, American Society of Anesthesiologists score, need for emergency operation, and the severity of peritonitis, have been described. ${ }^{35,36}$ The randomization provided an optimal distribution of all of those factors including co- morbidities and the severity of the septic disease within the 2 groups. The reason why more females than males were included in the study remains unclear. Analyzing the overall outcome of both procedures including the first (resection) and the second step (stoma reversal), we found comparable mortality (13\% in HP an $9 \%$ in PA) and morbidity rates based on a therapy-oriented complication score. ${ }^{37}$ Other outcome parameters, such as intraoperative parameters, hospital stay, ICU stay, and costs were equivalent, with the exception of the overall number of complications favoring the PA group. Long-term survival, which to our knowledge has never been analyzed in previous studies, was similar in both groups (5-year survival of $60 \%$ in HP and $62 \%$ in PA).

Focusing at the first operation (resection), mortality (13\% in $\mathrm{HP}$ and $9 \%$ in PA) and morbidity (66\% in HP and $75 \%$ in PA) and the rates of serious complications (grade $\geq 3 \mathrm{~b}$ : $40 \%$ in HP and $44 \%$ in PA) were equivalent in both groups. Interestingly, the number of intra-abdominal infections was higher in the group without colonic anastomosis. These figures are consistent with the literature on HP (mortality up to $28 \%$ and morbidity up to $70 \%$ ). ${ }^{38-40}$ It indicates that the inherent bias of the previous study did not prevent the correct evaluation favoring the PA strategy with protective ileostomy.

The main benefit of a PA with protective ileostomy compared with $\mathrm{HP}$ is the significantly higher stoma reversal rate $(57 \%$ in $\mathrm{HP}$ and $90 \%$ in PA), with no patients being lost to follow-up. The reasons for not having the stoma reversed were the operative risk assessment by the surgeon and the patient's choice. Two of 3 patients without stoma reversal in the PA group were deviated from PA to HP during the first operation; however, this analysis was performed on an intention-totreat basis. Very similar reversal rates can be found in the literature, $60 \%$ to $70 \%$ for $\mathrm{HP}^{41}$ and $90 \%$ for $\mathrm{PA} .{ }^{42}$ Although ileostomy reversal was not associated to fewer complications, the severity of complications was significantly lower than that in patients who underwent a reversal of their colostomy. In particular, none of the patients after ileostomy reversal required reoperation or ICU admission, whereas after colostomy reversal, 3 patients had to be reoperated because of intra-abdominal infection or bleeding; 1 required ICU admission due to pulmonary failure. Although this difference in outcome occurred 
(A) Types of complications related to the $1^{\text {st }}$ operation

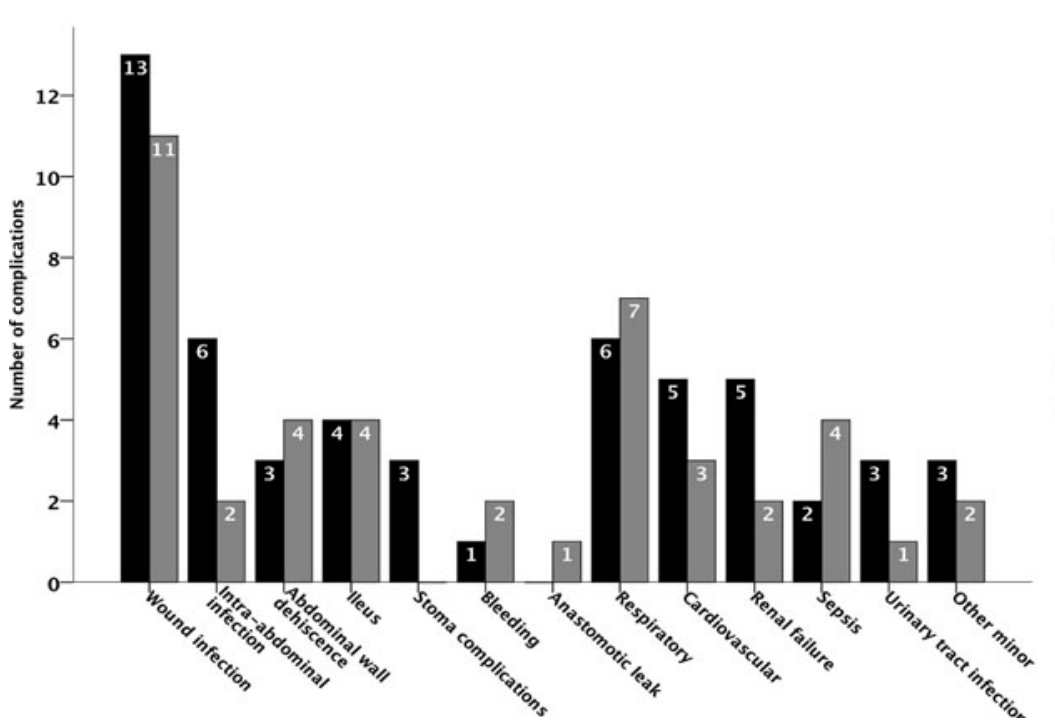

(B) Types of complications related to the reversal

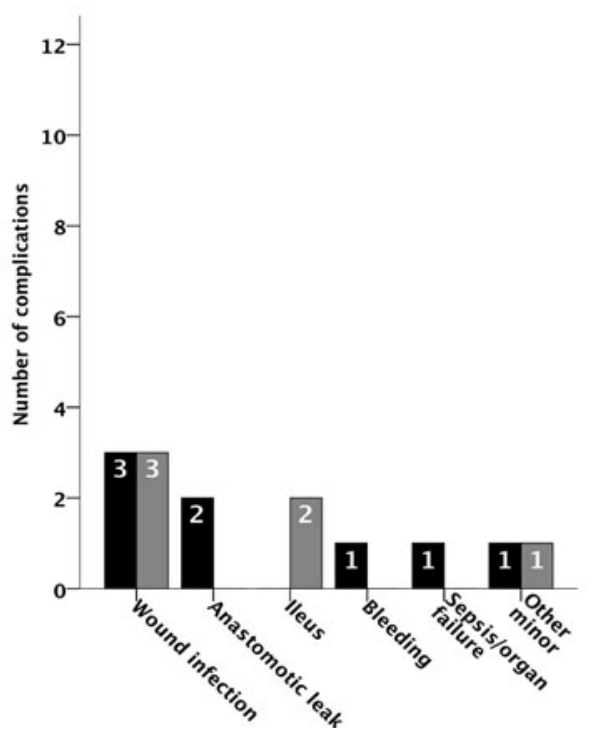

FIGURE 3. Types of complications associated to the first operation only (Hartmann's procedure (black bars) versus primary anastomosis with diverting ileostomy (gray bars)) (A) and types of complications associated to the second operation only (stoma reversal) (B). A, Types of complications related to the first operation. B, Types of complications related to the reversal.

in the HP group, only the patients who received a stoma reversal were considered at lower risk for perioperative complications. Obviously, the extensiveness of surgery to reverse an end colostomy after HP is higher than for a diverting ileostomy, which may explain not only the differences in complications but also the reduced operating time and hospital stay. The reason why the occurrence of serious complications was significantly different in the second operation (Table 4) but similar in the overall assessment of procedures (including both primary and secondary, Table 2 ) was that, according to the protocol, only 1 (most severe) complication was considered for the overall analysis. Those were mostly related to the resection operation.

The presented data confirm safety of PA in acute colonic perforation with severe peritonitis, but this trial is limited to the strategy including a diverting ileostomy. Therefore, the upcoming question whether a diverting ileostomy is necessary needs further investigation. Studies demonstrating low complication rates of PA without diverting ileostomy (24\%-84\%) ${ }^{10,41,43}$ include relevant selection bias toward low-risk patients with only localized (Hinchey II) or purulent (Hinchey III) peritonitis. ${ }^{42}$ Potential future studies comparing surgical approaches with and without a diverting stoma are challenging. Not only the ethical issue of comparing 1- and 2-step procedures needs to be addressed but also the risk of patient reluctance, imbalance in surgical expertise, and most importantly the poor compliance with the allocation. Even more difficult will be to comparatively assess the most recent therapeutic approach, which is the laparoscopic suturing of the colonic perforation and washout of the abdominal cavity. ${ }^{44,45}$ This minimally invasive approach is very innovative and revolutionary and is therefore gaining a lot of interest.

Another limitation of this study relates to the integration of several surgeons performing the operations. It is known that attributes of the surgeons, such as surgical knowledge, clinical training, experience, and inherent skills, could influence the surgical intervention and lead to variability in practice and health outcomes. ${ }^{46}$ However, the involvement of multiple surgeons, particularly those on call at the time of patient recruitment, reflects the reality because the urgent treatment of patients with acute colonic perforation belongs to the basic duties of most surgical departments. To minimize confounding related to surgeons' experience, all of the operations in both groups were performed by a surgical team including both a board-certified and a non-board-certified surgeon.

In conclusion, although the primary outcome did not differ between the 2 groups, this multicenter randomized clinical trial provides strong evidence favoring PA with protective ileostomy over HP in the treatment of acute left-sided colonic perforation with generalized peritonitis. The benefits directly relate to the stoma reversal operation, which is more likely to occur and safer in PA. Further investigations are required to identify a group of patients, which may potentially not require a diverting ileostomy.

\section{REFERENCES}

1. Young-Fadok TM. Diverticular disease of the Colon 2012. Available at: http://www.fascrs.org/physicians/education/core_subjects/2001/diverticular_ disease./ Accessed November 11, 2011.

2. Wong WD, Wexner SD, Lowry A, et al. Practice parameters for the treatment of sigmoid diverticulitis-supporting documentation. The Standards Task Force. The American Society of Colon and Rectal Surgeons. Dis Colon Rectum. 2000;43:290-297.

3. Seiler CA, Brugger L, Maurer CA, et al. Peritonitis in diverticulitis: the Bern concept. Zentralbl Chir. 1998;123:1394-1399.

4. Trenti L, Biondo S, Golda T, et al. Generalized peritonitis due to perforated diverticulitis: Hartmann's procedure or primary anastomosis? Int $J$ Colorectal Dis. 2011;26:377-384.

5. Constantinides VA, Heriot A, Remzi F, et al. Operative strategies for diverticular peritonitis: a decision analysis between primary resection and anastomosis versus Hartmann's procedures. Ann Surg. 2007;245:94-103.

6. Zorcolo L, Covotta L, Carlomagno N, et al. Safety of primary anastomosis in emergency colo-rectal surgery. Colorectal Dis. 2003;5:262-269.

7. Salem L, Flum DR. Primary anastomosis or Hartmann's procedure for patients with diverticular peritonitis? A systematic review. Dis Colon Rectum. 2004;47:1953-1964.

8. Abbas S. Resection and primary anastomosis in acute complicated diverticulitis, a systematic review of the literature. Int J Colorectal Dis. 2007;22:351-357.

9. Constantinides VA, Tekkis PP, Athanasiou T, et al. Primary resection with anastomosis vs. Hartmann's procedure in nonelective surgery for acute colonic diverticulitis: a systematic review. Dis Colon Rectum. 2006;49:966-981. 
10. Regenet N, Pessaux P, Hennekinne S, et al. Primary anastomosis after intraoperative colonic lavage vs. Hartmann's procedure in generalized peritonitis complicating diverticular disease of the colon. Int J Colorectal Dis. 2003;18:503507.

11. Vermeulen J, Coene PP, Van Hout NM, et al. Restoration of bowel continuity after surgery for acute perforated diverticulitis: should Hartmann's procedure be considered a one-stage procedure? Colorectal Dis. 2009;11:619-624.

12. Aydin HN, Remzi FH, Tekkis PP, et al. Hartmann's reversal is associated with high postoperative adverse events. Dis Colon Rectum. 2005;48:2117-2126.

13. Breitenstein S, Kraus A, Hahnloser D, et al. Emergency left colon resection for acute perforation: primary anastomosis or Hartmann's procedure? A casematched control study. World J Surg. 2007;31:2117-2124.

14. Casal Nunez JE, Ruano Poblador A, Garcia Martinez MT, et al. [Morbidity and mortality after a Hartmann operation due to peritonitis originating from a sigmoid diverticulum disease (Hinchey grade III-IV)]. Cir Esp. 2008;84:210 214.

15. Vermeulen J, Akkersdijk GP, Gosselink MP, et al. Outcome after emergency surgery for acute perforated diverticulitis in 200 cases. Dig Surg. 2007;24:361366.

16. Schulz KF, Altman DG, Moher D. CONSORT 2010 statement: updated guidelines for reporting parallel group randomised trials. BMJ. 2010;340:c332.

17. Hinchey EJ, Schaal PG, Richards GK. Treatment of perforated diverticular disease of the colon. Adv Surg. 1978;12:85-109.

18. Clavien PA, Barkun J, de Oliveira ML, et al. The Clavien-Dindo classification of surgical complications: five-year experience. Ann Surg. 2009;250:187-196.

19. Vonlanthen R, Slankamenac K, Breitenstein S, et al. The impact of complications on costs of major surgical procedures: a cost analysis of 1200 patients. Ann Surg. 2011;254:907-913.

20. Zorcolo L, Covotta L, Carlomagno N, et al. Toward lowering morbidity, mortality, and stoma formation in emergency colorectal surgery: the role of specialization. Dis Colon Rectum. 2003;46:1461-1467; discussion 1467-1468.

21. Gunnarsson U, Karlbom U, Docker M, et al. Proctocolectomy and pelvic pouch - is a diverting stoma dangerous for the patient? Colorectal Dis. 2004;6:23-27.

22. Edwards DP, Leppington-Clarke A, Sexton R, et al. Stoma-related complications are more frequent after transverse colostomy than loop ileostomy: a prospective randomized clinical trial. Br J Surg. 2001;88:360-363

23. Bakx R, Busch OR, Bemelman WA, et al. Morbidity of temporary loop ileostomies. Dig Surg. 2004;21:277-281.

24. Hallbook O, Matthiessen P, Leinskold T, et al. Safety of the temporary loop ileostomy. Colorectal Dis. 2002;4:361-364

25. Poon RT, Chu KW, Ho JW, et al. Prospective evaluation of selective defunctioning stoma for low anterior resection with total mesorectal excision. World J Surg. 1999;23:463-467; discussion 467-468.

26. Biondo S, Ramos E, Deiros M, et al. Prognostic factors for mortality in left colonic peritonitis: a new scoring system. J Am Coll Surg. 2000;191: 635-642.

27. Berghold A. Randomizer-web-based patient randomization service for multi-center clinical trials. Available at: http://www.randomizer.at. Accessed December 15, 2011

28. Charlson ME, Pompei P, Ales KL, et al. A new method of classifying prognostic comorbidity in longitudinal studies: development and validation. JChronic Dis. 1987;40:373-383.

29. Linder MM, Wacha H, Feldmann U, et al. [The Mannheim peritonitis index. An instrument for the intraoperative prognosis of peritonitis]. Chirurg. 1987;58:84-92.

30. Zeitoun G, Laurent A, Rouffet F, et al. Multicentre, randomized clinical trial of primary versus secondary sigmoid resection in generalized peritonitis complicating sigmoid diverticulitis. Br J Surg. 2000;87:1366-1374.

31. Kronborg O. Treatment of perforated sigmoid diverticulitis: a prospective randomized trial. Br J Surg. 1993;80:505-507.

32. Rodkey GV, Welch CE. Changing patterns in the surgical treatment of diverticular disease. Ann Surg. 1984;200:466-478.

33. Ergina PL, Cook JA, Blazeby JM, et al. Challenges in evaluating surgical innovation. Lancet. 2009;374:1097-1104.

34. Harrison JD, Solomon MJ, Young JM, et al. Surgical and oncology trials for rectal cancer: who will participate? Surgery. 2007;142:94-101.

35. Salem L, Anaya DA, Roberts KE, et al. Hartmann's colectomy and reversal in diverticulitis: a population-level assessment. Dis Colon Rectum. 2005;48:988995.

36. Tudor RG, Farmakis N, Keighley MR. National audit of complicated diverticular disease: analysis of index cases. Br J Surg. 1994;81:730-732.
37. Dindo D, Demartines N, Clavien PA. Classification of surgical complications: a new proposal with evaluation in a cohort of 6336 patients and results of a survey. Ann Surg. 2004;240:205-213.

38. Schilling MK, Maurer CA, Kollmar O, et al. Primary vs. secondary anastomosis after sigmoid colon resection for perforated diverticulitis (Hinchey Stage III and IV): a prospective outcome and cost analysis. Dis Colon Rectum. 2001;44:699-703; discussion 703-705

39. Krahn MD, Naglie G, Naimark D, et al. Primer on medical decision analysis: part 4-analyzing the model and interpreting the results. Med Decis Making. 1997; 17:142-151

40. Naimark D, Krahn MD, Naglie G, et al. Primer on medical decision analysis: part 5-working with Markov processes. Med Decis Making. 1997;17:152159.

41. Hold M, Denck H, Bull P. Surgical management of perforating diverticular disease in Austria. Int J Colorectal Dis. 1990;5:195-199.

42. Elliott TB, Yego S, Irvin TT. Five-year audit of the acute complications of diverticular disease. Br J Surg. 1997;84:535-539.

43. Auguste L, Borrero E, Wise L. Surgical management of perforated colonic diverticulitis. Arch Surg. 1985;120:450-452.

44. Afshar S, Kurer MA. Laparoscopic peritoneal lavage for perforated sigmoid diverticulitis. Colorectal Dis. 2012;14:135-142.

45. Bretagnol F, Pautrat K, Mor C, et al. Emergency laparoscopic management of perforated sigmoid diverticulitis: a promising alternative to more radical procedures. J Am Coll Surg. 2008;206:654-657.

46. Edmunds LH, Cohn LH. Cardiac Surgery in the Adult. New York: McGrawHill; 2004

\section{DISCUSSANTS}

\section{Y. Panis (Clichy, France):}

I think it is not very easy to criticize this study because it is the first randomized study to address this particular question. So, my first comment is to congratulate you on the study. I have a few short questions. First, do you think that this study is too late and that maybe the question today is laparoscopic lavage? My second question concerns the statistical analysis you made for the primary outcome, that is, overall complication rates. You expected a decrease from $70 \%$ to $40 \%$, and you got $80 \%$ and $84 \%$. In my view, the conclusion is that there is no difference and that primary anastomosis achieves exactly the same result as Hartmann's procedure. Because your primary end point is nonsignificantly different, how can you say that one is better than the other? In your intention-to-treat analysis, 3 patients $(10 \%)$ with primary anastomosis, in fact, had a Hartmann procedure. So, did you also analyze this to see, if you alter the results, whether these 3 patients were considered as being part of the Hartmann's group? I think, taking a pragmatic approach, it is difficult to understand that 3 patients with Hartmann's are analyzed as having a primary anastomosis. My last question concerns the practicalities of performing a primary anastomosis at midnight with a young surgeon. You know that is not always possible. In the chart flow, you excluded more than $50 \%$ of the patients because at the beginning you have 135 patients and included 68 patients in the study, so why did you exclude $50 \%$ of the patients?

\section{Response From S. Breitenstein (Zurich, Switzerland):}

Your first question concerns the laparoscopic approach to treat colonic perforation. Based on a series of feasibility trials, there is a trend toward a laparoscopic washout and suture of the perforated colonic perforation in selective cases of purulent peritonitis. However, the laparoscopic approach is not standard for the vast majority of patients suffering from colonic perforation, and it is not included in any guidelines of the most relevant international colorectal associations. Because there is a lack of evidence regarding the optimal treatment of colonic perforation, it is very important to provide randomized clinical trials. I do not consider it to be too late for our study. 
Regarding your second question, it is true that the results of the primary end point were similar. However, significant differences in clinically highly relevant secondary end points concerning the stoma reversal operation allow us to conclude that the primary anastomosis with protective diverting ileostomy is superior to the Hartmann's operation.

Your third question concerns the "intention-to-treat analysis" of the results. Indeed, a few patients were not operated upon in accordance with their randomization. But the results of this analysis did not differ when evaluated from an intention-to-treat approach.

Finally, you asked about the inclusion process of the study patients. It is important to differentiate between patients who were not assessed for eligibility and patients who were excluded during the eligibility assessment. The first aspect has to do with the clinical setting. We assessed emergency procedures in life-threatening situations mostly in the middle of the night. In such circumstances, surgeons are not really motivated to include patients in randomized trials. This reflects a recognized problem in clinical research. The second point, exclusion of patients during the assessment of eligibility, has to do with the fact that some patients did not meet the inclusion criteria or disagreed with participation in the study. This is part of every randomized clinical trial.

\section{E. Tiret (Paris, France):}

I think it is very difficult to give full information to the patient in this emergency situation. For instance, between the 2 arms in this study, there is a difference because in the Hartmann's group the patient is expected to keep his stoma during 3 or 4 months, and it is much easier to close the stoma after 2 months in the second arm. So, what information was given to the patient in this emergency situation?

Second, what did you do for the colon in the second arm between the ileostomy and the anastomosis? Did you perform a washout to clean the colon or not?

\section{Response From S. Breitenstein (Zurich, Switzerland):}

Regarding your first question, we basically planned, and communicated to the patients, that we wanted to reverse the stoma 6 to 10 weeks after colonic resection independent of the randomization to have a comparable time frame between the first and second operations in both groups. However, analyzing our data, we observed a longer time frame until stoma reversal in the Hartmann's group: 6 months compared with 3 months in the direct anastomosis group.
Concerning your second question, we did not standardize cleaning of the colon. Therefore, this was a decision of the individual surgeon. In the end, $50 \%$ of the surgeons cleaned the colon in the group of primary anastomosis.

\section{R. Margreiter (Innsbruck, Austria):}

I just wanted to bring to your attention a strategy that we developed, established in Innsbruck some years ago. As you say, in the middle of the night we see 3 or 4 patients, we do just resect the perforated part of the bowel, leave it at that, and 24 or 48 hours later we conduct a second look, and dependent on whether the infection is cleared or improved, we perform a primary anastomosis, otherwise we perform a Hartmann's procedure. That makes it even safer.

\section{Response From S. Breitensten (Zurich, Switzerland):} up to now.

That is an interesting concept, which we have not considered

\section{G. Carlson (Manchester, United Kingdom):}

You tried to show us that the level of illness in the 2 groups was the same at around the time of surgery. I think it would have been useful to see some more data on that, and, specifically, did you consider POSSUM scores and presenting your complication rates as a percentage of those that you would predict on a POSSUM score on the basis of acute physiological disturbance and chronic health?

Second, if I understand your data correctly, $40 \%$ of the patients who had Hartmann's procedure did not get them reversed. Ten percent of the patients who received loop ileostomies did not have them reversed. The problem with that, of course, is that the quality of life with a loop ileostomy is considerably worse than with a colostomy. You referred to quality of life in your discussion a moment ago, but I did not see any quality of life data. Did you compare the overall quality of life in the 2 groups; for those who did not have their stomas reversed, were they actually in fact the same?

\section{Response From S. Breitenstein (Zurich, Switzerland):}

These are important aspects, Prof. Carlson. We did not assess the POSSUM score. The severity of peritonitis and sepsis was evaluated on the basis of the Hinchey classification, Mannheim Peritonitis Index, and laboratory parameters.

Regarding your second comment, I agree that the quality of life with end colostomy is higher than with ileostomy. However, we did not perform a quality of life assessment in our patients. 